\title{
A qualitative description of shallow groundwater effect on surface temperature of bare soil
}

\author{
F. Alkhaier ${ }^{1}$, R. J. Schotting ${ }^{2}$, and Z. Su ${ }^{1}$ \\ ${ }^{1}$ Department of water resources, International Institute for Geo-information Science and Earth Observation, \\ Enschede, The Netherlands \\ ${ }^{2}$ Faculty of Geosciences, Utrecht University, Utrecht, The Netherlands
}

Received: 6 February 2009 - Published in Hydrol. Earth Syst. Sci. Discuss.: 9 March 2009

Revised: 21 August 2009 - Accepted: 13 September 2009 - Published: 30 September 2009

\begin{abstract}
Whether or not shallow groundwater affects skin temperature (the temperature of soil surface) is important to detect depth and extent of shallow groundwater by dint of remote sensing and important for land surface modelling studies. Although few studies have been conducted to investigate that effect, they have yielded contradicting conclusions and they stopped in 1982. To determine that shallow groundwater affects skin temperature, we measured soil temperature at two different depths $(5$ and $10 \mathrm{~cm}$ ) in seven places with variable water table depths every ten minutes and for six days. After that, we correlated the minimum, maximum and average daily temperatures to average groundwater depth. We also built a simple numerical model using a differential equations solver, Flex PDE, to simulate heat transfer into soil profile and used it to simulate groundwater effect on skin temperature. We found quite high negative correlation between the maximum and average daily soil temperature and groundwater depth. Contrarily, we could hardly find any correlation between the daily minimum temperature and groundwater depth. Numerical simulations, though simple, were useful in showing that groundwater shifted skin temperature curves up in the winter and down in the summer without affecting the shape of the curve. We conclude that shallow groundwater affects skin temperature directly by its distinctive thermal properties in the soil profile and indirectly by affecting soil moisture which in turn has many different and contradictory effects on skin temperature. This study recommends building a comprehensive numerical model that simulates the effect of shallow groundwater on skin temperature and on the different energy fluxes at land surface.
\end{abstract}

Correspondence to: F. Alkhaier (khaier@itc.nl)

\section{Introduction}

Whether or not shallow groundwater affects skin temperature is important in many aspects. Skin temperature is a key factor in solving surface energy balance and affects all its components (i.e. latent, sensible and ground heat fluxes). Besides, skin temperature is the only means through which thermal remote sensing can detect the existence, depth and extent of groundwater perching at shallow depths.

In spite of the numerous studies which have dealt with heat transfer and temperature distribution within the soil profile and at land surface, a few have investigated the effect of shallow groundwater on the behaviour of surface soil temperature.

Although Kappelmeyer (1957) could successfully use temperature measurements conducted at shallow $(1.5 \mathrm{~m})$ depth to locate fissures carrying hot water from deep groundwater, pioneering studies to locate shallow aquifers by geothermal measurements were initiated by Cartwright (1968), who correlated soil temperature at $0.5 \mathrm{~m}$ depth to the groundwater depths. A year later, Birman (1969) found that shallow earth temperatures could be related to the occurrence of groundwater.

Extending the method of Cartwright (1968), Cartwright (1974) included the detection of both the depth of shallow groundwater and the description of the velocity and direction of its flow. In this new method, temperature was measured at one meter depth. A few studies of utilizing soil temperature in groundwater survey were mentioned by Furuya et al. (2006); those studies (Takeuchi, 1980, 1981, 1996; Yuhara, 1998) developed the study of Cartwright (1974) into a practical method using soil temperature measured at one meter depth.

Published by Copernicus Publications on behalf of the European Geosciences Union. 
In 1972 the first attempt to map shallow groundwater was made using the brightness temperature retrieved from airborne radiometers of land surface by Myers and Moore (1972). They found that the correlation between land surface temperature and depths to groundwater was significant in a predawn imagery of 26 August 1971 taken under favourable weather and water table conditions (groundwater depth was between 1.5 and $4.5 \mathrm{~m}$ ). In comparison, Quiel (1975) restricted the groundwater depth to $20 \mathrm{~cm}$ to be detected by land surface temperature.

Huntley (1978) presented a critical and detailed study of the potential to detect groundwater from surface temperature measurements. He developed a mathematical model to describe the heat flux and temperature distribution in the soil column and concluded that this detection was not promising with the technology presented at that time. He explained that the minimum detectable temperature contrast using a thermal infrared scanner was in the order of $0.5^{\circ} \mathrm{C}$, while the minimum detectable change of groundwater depth under the best conditions according to his model was in the same order of magnitude.

The most recent study investigating the effect of groundwater on skin temperature that could be found in the literature was Heilman and Moore's (1982 - four years after Huntley's). They showed again that radiometric temperature measurements could be correlated to depth to shallow groundwater if appropriate considerations were given to the effect of vegetation on the surface thermal regime. They also recommended that techniques for distinguishing water table influences from those of soil moisture should be developed to make the temperature method works for groundwater studies.

The concern of many of the surveyed studies was the depth in the soil column $(0.5-1.5 \mathrm{~m})$ to investigate the effect of shallow groundwater on soil temperature. Other studies which focused on the effect of shallow groundwater on skin temperature were few and yielded contradicting results. And most importantly, they have ceased since 1982 .

The objective of this paper is to show the effect of shallow groundwater on skin temperature by field measurements and to examine the reason behind this effect with a simple numerical model. A detailed numerical model, that can simulate the energy balance components and solve this balance for skin temperature and soil moisture, needs a very complex numerical modelling effort, and is beyond the scope of this paper.

In this study the relationship between soil temperature close to the surface $(5$ and $10 \mathrm{~cm}$ ) and water table depth was investigated by correlating the daily minimum, maximum and average soil temperature readings to water table depth. To simulate the effect of shallow groundwater on skin temperature, a one dimension transient heat transport model was built using Flex PDE (PDE Solutions, Inc.), a scripted finite element model builder and numerical solver. This model turned out to be useful for explaining and justifying the rea- son behind the effect of shallow groundwater on land surface temperature.

\section{Theory}

Soil temperature at land surface (i.e. skin temperature) is an outcome of the equilibrium among the different forms of energy transfer and exchange that occur at the very top soil; this equilibrium is usually described by the surface energy balance equation:

$R_{n}=G+H+L E$

Where $G\left(\mathrm{~W} \mathrm{~m}^{-2}\right)$ is the ground heat flux, $H\left(\mathrm{~W} \mathrm{~m}^{-2}\right)$ is the sensible heat flux, $L E\left(\mathrm{~W} \mathrm{~m}^{-2}\right)$ is the latent heat flux and $R_{n}\left(\mathrm{~W} \mathrm{~m}^{-2}\right)$ is the net radiation which is calculated by using Eq. (2):

$R_{n}=K_{\text {in }}-K_{\text {out }}+L_{\text {in }}-L_{\text {out }}$

Where $K_{\text {in }}$ and $K_{\text {out }}\left(\mathrm{W} \mathrm{m}^{-2}\right)$ are respectively the incoming and outgoing short-wave radiation, and $L_{\text {in }}$ and $L_{\text {out }}$ $\left(\mathrm{W} \mathrm{m}^{-2}\right)$ are the incoming and outgoing long-wave radiation, respectively.

After subtracting the sensible and the latent heat fluxes from the net radiation the resultant is considered as ground heat flux: the flux that is of prime responsibility of controlling soil temperature in the absence of inner energy sources (i.e. nuclear minerals, magma eruption, hot springs etc.), then we write:

$G=R_{n}-H-L E$

Daily $G$ can be described analytically under periodic forcing assumption (Horton and Wierenga, 1983; Santanello and Friedl, 2003) as:

$G_{\text {daily }}=k \cdot A_{1} \cdot \sqrt{\frac{2 \cdot \pi}{\alpha \cdot p_{1}}} \cdot \sin \left(\frac{2 \cdot \pi \cdot t}{p_{1}}+\frac{\pi}{4}\right)$

This can be extended to describe the yearly $G$ by:

$$
\begin{aligned}
G_{\text {yearly }} & =k \cdot\left[A_{1} \cdot \sqrt{\frac{2 \cdot \pi}{\alpha \cdot p_{1}}} \cdot \sin \left(\frac{2 \cdot \pi \cdot t}{p_{1}}+\frac{\pi}{4}\right)+A_{2} \cdot \sqrt{\frac{2 \cdot \pi}{\alpha \cdot p_{2}}}\right. \\
& \left.\cdot \sin \left(\frac{2 \cdot \pi \cdot t}{p_{2}}+\frac{\pi}{4}\right)\right]
\end{aligned}
$$

Where $k\left(\mathrm{~J} \mathrm{~m}^{-1} \mathrm{sec}^{-1 \circ} \mathrm{C}^{-1}\right)$ and $\alpha\left(\mathrm{m}^{2} \mathrm{sec}^{-1}\right)$ are the average soil thermal conductivity and thermal diffusivity. $A_{1}$ and $A_{2}\left({ }^{\circ} \mathrm{C}\right)$, respectively, are the daily and yearly temperature amplitudes at land surface respectively, $p_{1}$ is one day and $p_{2}$ is one year expressed in the time unit of the equation ( $\mathrm{sec}$ ).

As soon as heat penetrates the soil its transfer is well described by the heat diffusion equation:

$\frac{\partial(k \cdot \partial T)}{\partial^{2} z}=\mathrm{VHC} \cdot \frac{\partial T}{\partial t}$ 


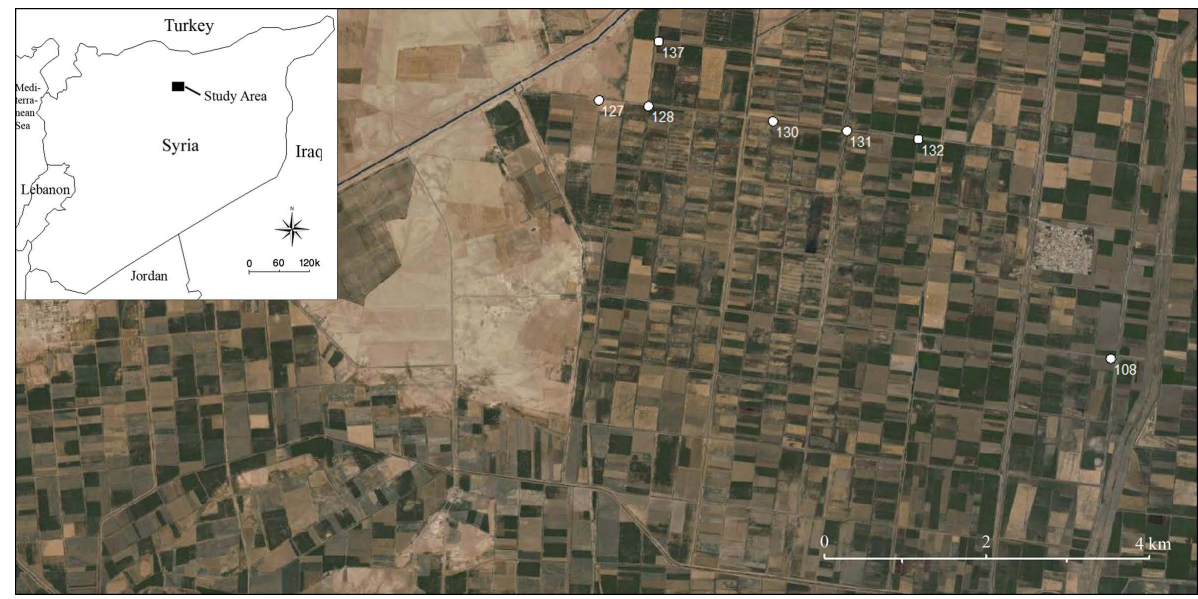

Fig. 1. Study area with observation sites (Google Earth image).

Where $k$ is the thermal conductivity $\left(\mathrm{J} \mathrm{m}^{-1} \mathrm{sec}^{-1{ }^{\circ}} \mathrm{C}^{-1}\right), T$ is temperature $\left({ }^{\circ} \mathrm{C}\right), z$ is depth $(\mathrm{m}), V H C$ is the volumetric heat capacity $\left(\mathrm{J} \mathrm{m}^{-3 \circ} \mathrm{C}^{-1}\right)$ and $t$ is time (sec).

Values of thermal conductivity and volumetric heat capacity can be calculated by using the method of de Vries (de Vries, 1963; Wierenga and de Wit, 1970). According to this method and depending on the physical properties of the soil components (i.e. air, water, minerals and organic matter) thermal conductivity can be expressed as:

$k=\frac{\sum_{i=0}^{n} k_{i} \cdot X_{i} \cdot \phi_{i}}{\sum_{i=0}^{n} k_{i} \cdot X_{i}}$

And volumetric heat capacity can be described as:

$\mathrm{VHC}=\sum_{i=0}^{n} \mathrm{VHC}_{i} \cdot X_{i}$

Where $X_{i}(-)$ is the volumetric fraction of each soil component, $k_{i}\left(\mathrm{~J} \mathrm{~m}^{-1} \mathrm{sec}^{-1{ }^{\circ}} \mathrm{C}^{-1}\right)$ is its thermal conductivity, $\phi_{i}$ (-) is its shape factor, $\mathrm{VHC}_{i}\left(\mathrm{~J} \mathrm{~m}^{-3 \circ} \mathrm{C}^{-1}\right)$ is its volumetric heat capacity and $n$ is the number of the soil components.

Groundwater existence within the soil profile is expressed by the distinctive values of both thermal conductivity and volumetric heat capacity of the saturated soil. Saturated soils naturally have high values of both.

\section{Methods and materials}

\subsection{Field measurements}

Field measurements were conducted in an agricultural area that lies within Euphrates basin in the north part of Syria (Fig. 1). The boundaries of this area stretch between longitude $38^{\circ} 43^{\prime}$ to $39^{\circ} 03^{\prime} \mathrm{E}$ and latitude $35^{\circ} 55^{\prime}$ to $36^{\circ} 13^{\prime} \mathrm{N}$.
The agricultural fields are equipped with irrigation canals and drainage conduits. Groundwater level has been monitored by means of a dense network of observation piezometers.

Arid conditions prevail in the region with an average annual rainfall less than $200 \mathrm{~mm}$ and average free water surface evaporation ranging between $1.4 \mathrm{~mm} /$ day in January and $14.3 \mathrm{~mm} /$ day in July (Alkhaier, 2003).

Pedological data show that silty clay soils cover most of the fields. The poor hydraulic permeability of these soils together with existence of a heavy clay layer at approximately ten meters depth make the groundwater generally perch at shallow depths all year around.

In January 2008 (winter time) seven locations (Fig. 1) with dissimilar water table depths were chosen. In each location, two temperature loggers were deployed in the soil at two different depths (approximately 5 and $10 \mathrm{~cm}$ ). The loggers recorded temperature every ten minutes for almost six days duration. However, taking into account only the full 24-h days restricted the data to five days.

Upon loggers' deployment, water table depths were measured, soil samples of the upper $5 \mathrm{~cm}$ were taken to the laboratory for texture analysis and soil moisture determination.

To omit the effect of soil moisture difference on soil temperature among the measurement locations, soils at the loggers' locations were watered until saturated immediately before the last day of the experiment. The temperature of the applied water was just above the freezing point, as it was taken from the nearby irrigation canals where water froze at the surface of these canals.

To explore the relationship between groundwater depth and temperature oscillations of soil at land surface, correlation coefficients were calculated between, on one hand, the maximum, minimum and average daily soil temperatures, and the average water table depths for a year backward, on the other. Further on, the p-values (Schervish, 1996) were calculated to test the significance of the above resultant 
Table 1. Correlation coefficients between the min, max and average daily temperatures at the two depths $(5$ and $10 \mathrm{~cm})$ and average water table depths.

\begin{tabular}{lcccccc}
\hline & \multicolumn{2}{c}{$\begin{array}{c}\text { Minimum } \\
\text { temperature }\end{array}$} & \multicolumn{2}{c}{ Maximum } & \multicolumn{2}{c}{ Average } \\
& $5 \mathrm{~cm}$ & $10 \mathrm{~cm}$ & $5 \mathrm{~cm}$ & $10 \mathrm{~cm}$ & $5 \mathrm{~cm}$ & $10 \mathrm{~cm}$ \\
\hline day 1 & 0.03 & -0.07 & -0.85 & -0.78 & -0.69 & -0.69 \\
day 2 & 0.06 & -0.14 & -0.85 & -0.77 & -0.73 & -0.76 \\
day 3 & 0.08 & -0.11 & -0.83 & -0.75 & -0.70 & -0.77 \\
day 4 & 0.04 & -0.28 & -0.71 & -0.67 & -0.72 & -0.78 \\
day 5 & 0.22 & -0.03 & -0.75 & -0.66 & -0.55 & -0.68 \\
\hline
\end{tabular}

correlations. In addition, the maximum, minimum and average daily temperatures at the different sites of measurement for two days (day 3, as a representative of the four dry days, and day 5, the wet day) were plotted against the average water table depths. Also, soil moisture values of the upper $5 \mathrm{~cm}$ at the different locations were plotted against average water table depths.

\subsection{Numerical simulations}

Flex PDE, a scripted finite element model builder and partial differential equations numerical solver, has been utilized to simulate heat transfer (Eq. 6) in one dimension of the soil profile. Supposing that groundwater existence within the soil profile does not affect the energy balance at land surface, the same $G$ (Eq. 5) was applied as an upper boundary condition (Neumann boundary condition) at the top of two different profiles:

- The first has no groundwater. So, it has a single value of thermal conductivity and another single value for volumetric heat capacity (please note that we simplify the simulation by assuming that the soil profile is homogenous with invariant soil thermal properties).

- But, the second profile has shallow groundwater perching at different depths (one, two, three, four and five meters, respectively) from land surface downwards. Therefore, it has two different sections with different values of both thermal conductivity and volumetric heat capacity. Values of thermal conductivity and volumetric heat capacity of the unsaturated part of the second profile were given exactly the same values of the first (dry) profile.

The lower boundary condition at ten meters depth (approximately the yearly penetration depth of heat) was set as a fixed temperature of $22^{\circ} \mathrm{C}$ (Dirichlet boundary condition), which is the annual deep soil temperature of the region.

The two simulations were run for one year duration, after one year of pre-simulation to reach the actual initial bound-
Table 2. P-values for the Correlation coefficients of Table 1.

\begin{tabular}{|c|c|c|c|c|c|c|}
\hline & \multicolumn{2}{|c|}{$\begin{array}{l}\text { Minimum } \\
\text { temperature }\end{array}$} & \multicolumn{2}{|c|}{$\begin{array}{l}\text { Maximum } \\
\text { temperature }\end{array}$} & \multicolumn{2}{|c|}{$\begin{array}{c}\text { Average } \\
\text { temperature }\end{array}$} \\
\hline & $5 \mathrm{~cm}$ & $10 \mathrm{~cm}$ & $5 \mathrm{~cm}$ & $10 \mathrm{~cm}$ & $5 \mathrm{~cm}$ & $10 \mathrm{~cm}$ \\
\hline day 1 & 0.95 & 0.89 & 0.02 & 0.04 & 0.09 & 0.09 \\
\hline day 2 & 0.89 & 0.77 & 0.02 & 0.04 & 0.06 & 0.05 \\
\hline day 3 & 0.86 & 0.81 & 0.02 & 0.04 & 0.08 & 0.04 \\
\hline day 4 & 0.93 & 0.54 & 0.08 & 0.10 & 0.07 & 0.04 \\
\hline day 5 & 0.63 & 0.95 & 0.05 & 0.11 & 0.20 & 0.09 \\
\hline
\end{tabular}

ary condition. The resultant skin temperature of the two profiles was then compared to each other.

\section{Results}

\subsection{Results from field measurements}

Table 1 contains the correlation coefficients between, on one hand, the maximum, minimum and average daily temperatures at the two depths $(5 \mathrm{~cm}$ and $10 \mathrm{~cm})$ and the average water table depths for a year before, on the other. And Table 2 contains the p-values corresponding to the correlation coefficient of Table 1.

We can see that the correlation coefficients values of the minimum temperatures are very low and have contradicting signs (negative and positive) between $5 \mathrm{~cm}$ and $10 \mathrm{~cm}$, while those for maximum and average temperatures are high and have negative sign. Another remark can be elicited here that the values of the correlation coefficients did not change significantly in the last day when the soils were saturated.

Studying the p-values in Table 2, we notice that the high correlation coefficients for the maximum and average temperatures have very small values of $p$-values. The observation that most of these values are smaller than 0.10 , and many are smaller than 0.05 , indicates that those high values of correlation coefficients are statically significant. At the same time we notice that the p-values corresponding to the low values of correlation coefficients for the minimum temperatures are large, which is understandable as there is no correlation for those minimum temperatures.

To inspect the relationship between soil temperature oscillations and water table depth schematically, the maximum, minimum and average daily temperatures plotted against the average water table depths at the different measurement sites for the third day (chosen randomly out of the four dry days) are shown in Fig. 2, and for the last day (wet day) in Fig. 3. Depending on these figures, one can recognise that the deeper the water table is the lower the maximum and average values of soil temperature are. Whereas, the relationship between the minimum temperatures and the water table depth might hardly exist. 

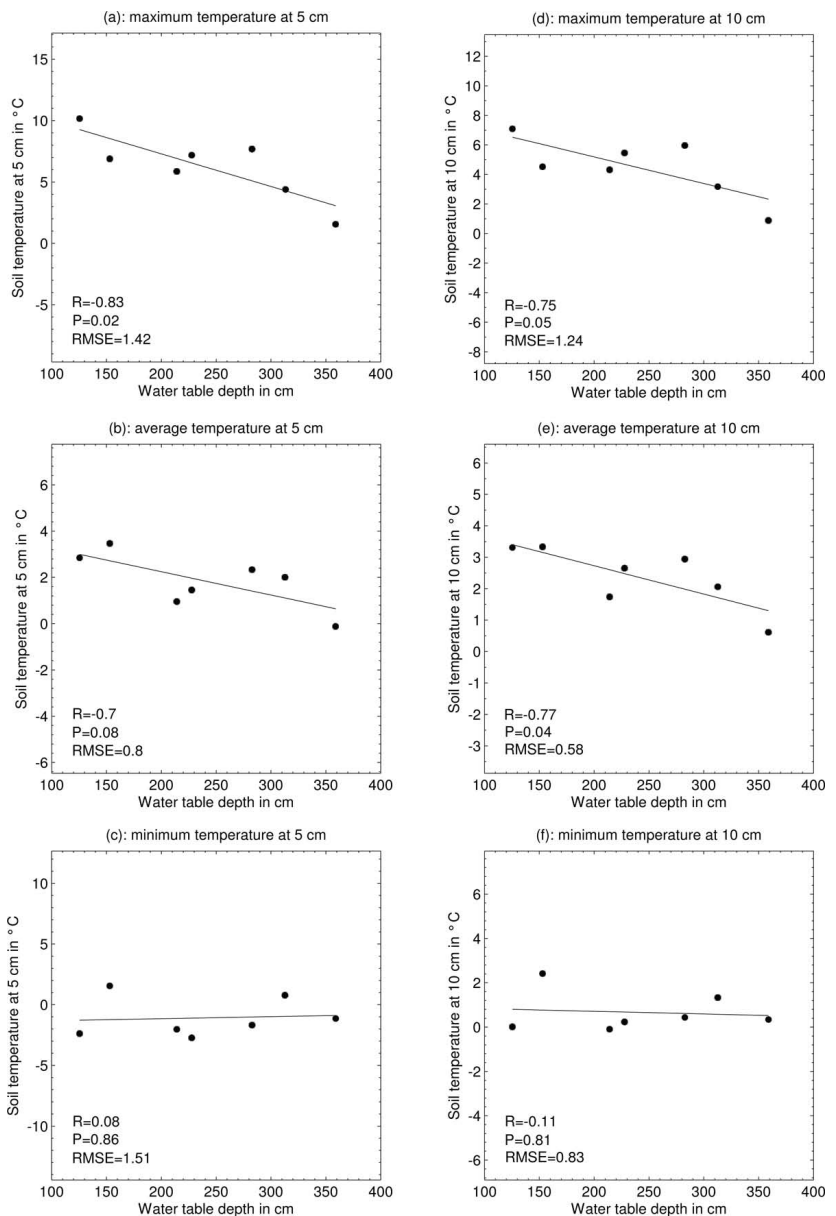

Fig. 2. Min, max and average temperature vs. water table depth of the third day for temperature measurements at $5 \mathrm{~cm}$ and $10 \mathrm{~cm}$ depth.

For both figures, it is clear that the maximum temperature has the highest correlation coefficient followed by the average temperature, while the minimum temperature has very low correlation coefficient. Moreover, there is no drastic change in the correlation coefficients before and after wetting the soils.

Figure 4 shows the relationship between volumetric soil moisture of the upper $5 \mathrm{~cm}$ measured at the seven different locations and the average water table depth. It can be seen that soil moisture decreases when the depth to groundwater increases.

\subsection{Results from numerical simulations}

Values of thermal conductivity $\left(\mathrm{J} \mathrm{m}^{-1} \mathrm{sec}^{-1}{ }^{\circ} \mathrm{C}^{-1}\right)$ and volumetric heat capacity $\left(\mathrm{J} \mathrm{m}^{-3 \circ} \mathrm{C}^{-1}\right)$ of the dry and saturated sections of the simulated profiles, calculated using Eqs. (7) and (8) are shown in Table 3.

To give the reader an impression of the range and the shape of the simulated skin temperature oscillation investigated in
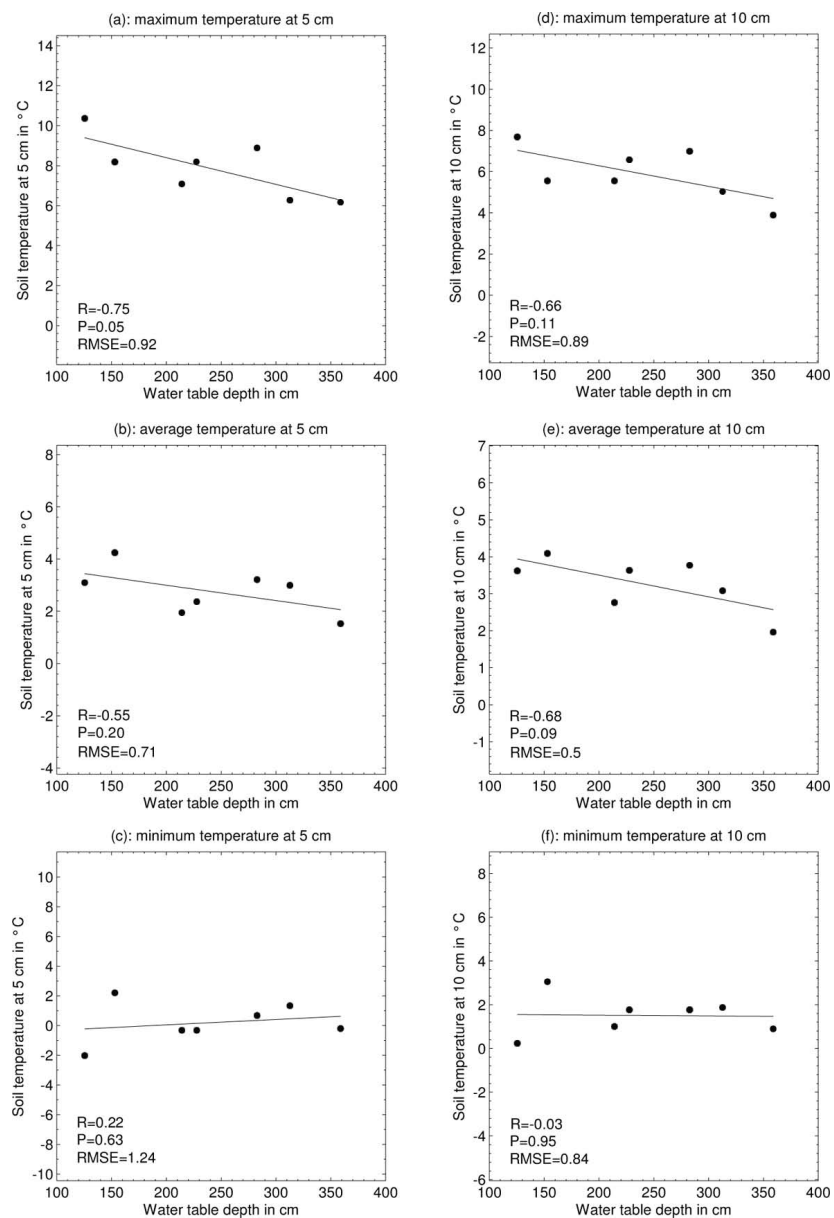

Fig. 3. Min, max and average temperature vs. water table depth of the last day (wet soil) for temperature measurements at $5 \mathrm{~cm}$ and $10 \mathrm{~cm}$ depth.

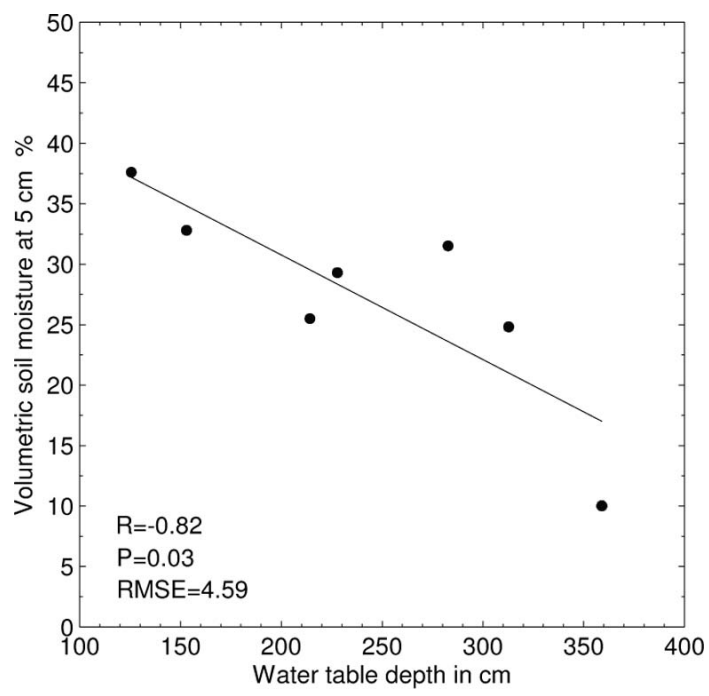

Fig. 4. Soil moisture of the upper $5 \mathrm{~cm}$ vs. water table depth. 
Table 3. Soil thermal properties used in the simulation.

\begin{tabular}{lcc}
\hline & $\begin{array}{c}\text { Thermal } \\
\text { Conductivity } \\
\left(\mathrm{J} \mathrm{m}^{-1} \mathrm{sec}^{-1 \circ} \mathrm{C}^{-1}\right)\end{array}$ & $\begin{array}{c}\text { Volumetric } \\
\text { Heat Capacity } \\
\left(\mathrm{J} \mathrm{m}^{-3 \circ} \mathrm{C}^{-1}\right)\end{array}$ \\
\hline Dry Soil & 0.72 & $1.21 \mathrm{E}+06$ \\
Saturated Soil & 1.27 & $3.10 \mathrm{E}+06$ \\
\hline
\end{tabular}

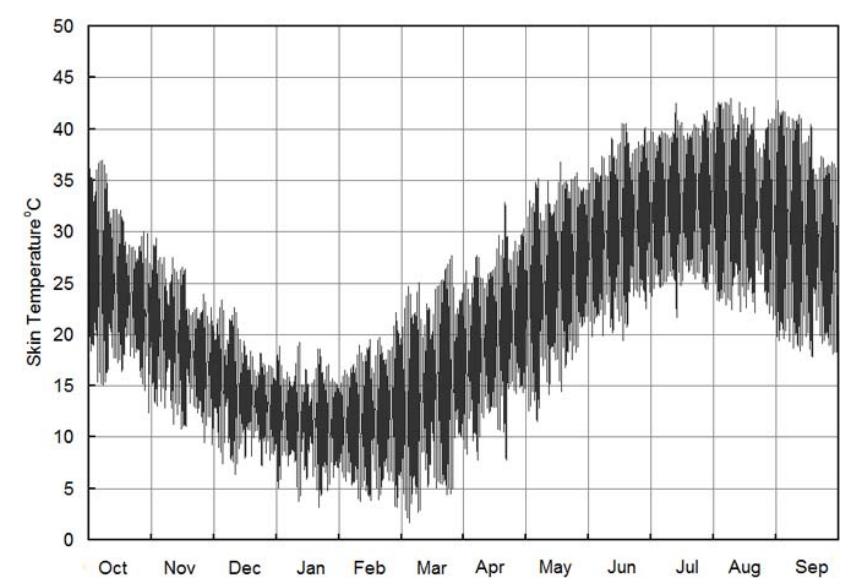

Fig. 5. Skin temperature oscillations of the simulated year.

this hypothetical numerical experiment, we present in Fig. 5 the skin temperature of the dry profile for the simulated year which begins in October. We can observe that the lowest temperatures occur in February and the highest in August.

The difference between the simulated values (skin temperature of the profile with groundwater perching at one meter, minus the skin temperature of the dry profile) is shown in Fig. 6.

Several remarks can be elicited from this graph, firstly, there is no oscillation in the values of difference, meaning that the skin temperatures of the two simulations are shifting up or down without changing their daily amplitudes. Secondly, the difference is positive in months from January to May, and reaches its maximum value of $3^{\circ} \mathrm{C}$ in March. Thirdly, the difference is negative in months from July to November and reaches its minimum value of $-3^{\circ} \mathrm{C}$ in September, and finally there are two months (namely December and June) when the difference is at lower values.

Values of maximum differences between the dry profile and the simulated profiles with different water tables are $1.5^{\circ} \mathrm{C}$ for $2 \mathrm{~m}$ depth, $0.8^{\circ} \mathrm{C}$ for $3 \mathrm{~m}$ depth, $0.4^{\circ} \mathrm{C}$ for $4 \mathrm{~m}$ depth and $0.2^{\circ} \mathrm{C}$ for $5 \mathrm{~m}$ depth. Naturally, these water depths include the capillary rise value.

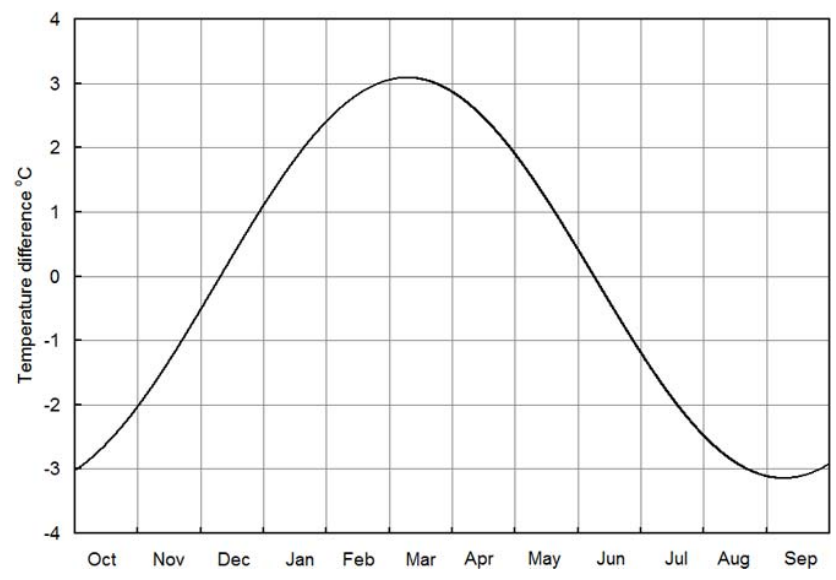

Fig. 6. The difference between the simulated skin temperatures of the two profiles (skin temperature of the profile with groundwater perching at one meter, minus the skin temperature of the dry profile).

\section{Discussion and conclusions}

In this study, we observe that shallow groundwater affects skin temperature. This is evidenced firstly, by the statistically significant high correlation between daily maximum and average soil temperatures and water table depth (Tables 1 and 2, Figs. 2 and 3), and secondly, by the difference in simulated skin temperatures caused by groundwater perching within the relevant soil profile (Fig. 6).

It is difficult and expensive to measure skin temperature in situ for different locations simultaneously. However, in terms of the fact that the heat diffusion equation (Eq. 6) is the master governing equation of heat transfer in the soil, the recorded temperatures at 5 and $10 \mathrm{~cm}$ can be considered as filtered signals of the temperatures at land surface. Further on, the correlations we've obtained can be safely considered valid for skin temperature because of the homogeneity of the soil and meteorological conditions in the region.

There are still other potential factors behind these correlations. For instance, elevation difference can influence both soil temperature and groundwater depth and lower elevation can be related to higher air temperature and shallower groundwater depth. However, the study area is flat and limited. The difference in elevation among the seven locations is less than five meters, and the furthest distance among them is less than seven kilometres (Fig. 1). That is why we ignore any effect of the difference in elevation or air temperature.

Although both field measurements and numerical simulations show that shallow groundwater affects the temperature oscillation at land surface, their results are not exactly the same. While the simulated skin temperature difference (Fig. 6) shows no daily oscillation i.e. groundwater existence shifts equally the whole daily temperature curve up (in winter) or down (in summer) without affecting the amplitude 
of the curve, field measurements show that the amplitudes of temperature curves are affected by shallow groundwater. That is lucid from the different values of correlation coefficients of the minimum, maximum and average daily temperature with water table depth (Table 1).

The dissimilarity between the two results is due to the simplicity of our numerical experiment. Firstly, it did not include and solve for the energy balance at land surface: instead, the same ground heat flux was applied as a boundary condition in both cases: with and without groundwater. In fact, when shallow groundwater affects skin temperature it affects all the components of the energy balance including ground heat flux. Secondly, it did not take into account the soil moisture effect: not only does shallow groundwater affect skin temperature directly by influencing heat flow within soil due to its distinctive thermal properties, but also it affects skin temperature indirectly by increasing soil moisture due to capillary rise and vapour transport within soil pores. This is apparent in Fig. 4, where soil moisture values increase with decreasing water table depth.

Soil moisture affects soil temperature in different and contradicting aspects. These effects fall into five categories: soil surface albedo, soil emissivity, evaporation, soil thermal conductivity and volumetric heat capacity. Firstly, increasing soil moisture decreases albedo which in turn increases the absorbed radiation during day time; hence, this increases daytime temperature. Secondly, soil emissivity increases with increasing soil moisture, which in turn increases the upward emission thus decreases surface temperature. Thirdly, the increase of soil moisture increases actual evaporation which accordingly decreases temperature. Fourthly, the increase of soil moisture increases soil thermal conductivity which eases heat transfer down and up within the surface soil and thereby decreases the absolute values of daily maximum and minimum temperatures. Finally, the increase of soil moisture increases soil volumetric heat capacity which increases the energy required for raising or lowering soil temperature, and in a similar manner to that of the third effect, it decreases the absolute values of the daily maximum and minimum temperatures.

On the last day of the experiment all locations were wetted until saturation. Consequently, the difference in soil moisture effects among the different locations was almost vanished. However, the relationship between soil temperature and water table depth (Tables 1 and 2, Figs. 2 and 3) was not affected considerably. This clarifies the direct effect of groundwater on skin temperature.

An unexpected phenomenon is worth mentioning here. Despite the general awareness that in daytime, wet soil must have lower temperature than dry one (due to its higher actual evaporation and higher heat capacity), the correlation between water table depth and maximum temperature was negative (Figs. 2 and 3) and so was it for soil moisture (Fig. 4). That means the observed maximum temperature was higher in wetter soils. Although this is counterintuitive, this obser- vation does agree with the simulation results in Fig. 6, which show warmer surface temperatures during the winter for the profile with shallow groundwater. This phenomenon would be sensible if we refer to evaporation and its cooling effect during winter as minimal.

In summary, we conclude that shallow groundwater affects skin temperature on yearly basis. As mentioned in many previous studies it acts like a heat sink in summer and a heat source in winter. However, due to the complex processes that take place at land surface (radiations and fluxes interactions) its effect is not simple to describe. Many studies avoided this complexity by going with their measurements deep into the soil to correlate groundwater existence to soil temperature. And the other studies which dealt with skin temperature had different opinions and contradicting results. Through the results of this study, we show that shallow groundwater has a clear impact on skin temperature. This impact will be useful in two fields: first, in utilizing thermal satellite remote sensing in groundwater studies and second, in land surface energy balance studies (land surface models and climate models).

In this study we show qualitatively that shallow groundwater affects skin temperature. Thus, we recommend setting a comprehensive numerical model that takes into account all the different factors which contribute to determining skin temperature and the exact magnitude of that effect.

Finally, we have noticed that the studies which utilized remote sensing for detecting depth to groundwater used a single scene (i.e. one reading). This study proves that a single scene/reading only is not sufficient, and recommends having a high temporal resolution of temperature measurements to detect shallow groundwater depth.

Acknowledgements. We are grateful to S. Salama, C. van der Tol, A. Gieske, Y. Zeng and W. Timmermans from the International Institute for Geo-information Science and Earth Observation, Enschede, the Netherlands, for helpful discussions. Also we appreciatively acknowledge the assistance in field measurements of T. Al Nayef and H. Al Eesa from the General Organization for Land Reclamation, Syria.

Edited by: J. Wen

\section{References}

AlKhaier, F.: Soil salinity detection using satellite remote sensing, M.S. thesis, International Institute for Geo-Information Science and Earth Observation, Enschede, The Netherlands, 70 pp., 2003.

Birman, H.: Geothermal exploration for groundwater, Geol. Soc. Am. Bull., 80(4), 617-630, 1969.

Cartwright, K.: Thermal prospecting for groundwater, Water Resour. Res., 4(2), 395-401, 1968.

Cartwright, K.: Tracing shallow groundwater systems by soil temperatures, Water Resour. Res., 10(4), 847-855, 1974.

de Vries, D. A.: Thermal properties of soils, in: Physics of Plant Environment, North Holland publication company, Amsterdam, 210-235, 1963. 
Furuya, G., Suemine, A., Sassa, K., Komatsubara, T., Watanabe, N., and Marui, H.: Relationship between groundwater flow estimated by soil temperature and slope failures caused by heavy rainfall, Shikoku Island, south western Japan, Eng. Geol., 85, 332-346, doi:10.1016/j.enggeo.2006.03.002, 2006.

Heilman, J. L. and Moore, D. G.: Evaluating depth to shallow groundwater using heat capacity mapping mission (HCMM) data, Photogrammetric Engineering and Remote Sensing, 48(12), 1903-1906, 1982.

Horton, R. and Wierenga, P. J.: Estimating the soil heat flux from observations of soil temperature near the surface, Soil Sci. Soc. Am. J., 47, 14-20, 1983.

Huntley, D.: On the detection of shallow aquifers using thermal infrared imagery, Water Resour. Res., 14(6), 1075-1083, 1978.

Kappelmeyer, O.: The use of near surface temperature measurements for discovering anomalies due to causes at depths, Geophysical Prospective, 5(3), 239-258, 1957.

Myers, V. I. and Moore, D. G.: Remote sensing for defining aquifers in glacial drift, Eighth International Symposium on Remote Sensing of Environment, volume 1, University of Michigan, 715-728, 1972.

Quiel, F.: Thermal/IR in geology, Photogram. Engi. Rem. Sens., 41(3), 341-346, 1975.
Santanello, J. A. and Friedl, M. A.: Diurnal covariation in soil heat flux and net radiation, J. Appl. Meteorol., 42, 851-862, 2003.

Schervish, M. J.: P-values: what they are and what they are not, The American Statistician, 50(3), 203-206, doi:10.2307/2684655, 1996.

Takeuchi, A.: Method of investigating groundwater-vein-streams by measuring one-meter-depth in landslide areas (I), Journal of Japanese Association of Groundwater Hydrology, 22(2), 11-39, 1980.

Takeuchi, A.: Method of investigating groundwater-vein-streams by measuring one-meter-depth in landslide areas (II), Journal of Japanese Association of Groundwater Hydrology, 23(1), 1-27, 1981.

Takeuchi, A.: Investigation methods of flowing groundwater by temperature measurements, Kokon Shoin, 367-468, 1996 (in Japanese).

Wierenga, P. J. and Wit, C. T. De: Simulation of heat transfer in soils, Soil Sci. Soc. Am. J., 34, 845-848, 1970.

Yuhara, K.: Isothermal layer, Groundwater handbook, revised version, edited by: Editorial committee of Groundwater handbook, Kensetsu Sangyo Chosakai, 1998 (in Japanese). 